\title{
Multiple Bone Hemangiomas Presenting As Bony Metastasis of Unknown Primary
}

\author{
EHABDAOUD
}

\begin{abstract}
Bone hemangiomas are rare benign tumors of the bones of vascular origin. A patient with bony pains and abnormal radiological findings is described. Following an unsuccessful extensive search for primary malignancy the patient was diagnosed as multiple bone hemangioma. This case serves as a reminder for considering benign causes of bone lesion while investigating cases with such presentation.
\end{abstract}

Keyword: Hemangioma, multiple, sclerosing hemangioma, back pain

\section{Introduction}

Bone hemangiomas are rare benign tumors that are usually asymptomatic, rarely recognized and seldom diagnosed non invasively. A high index of suspicion is warranted in any patient who is presenting with bone pains and multiple bony lesions on radiological imaging to avoid unnecessary expensive and invasive tests.

A rare case report is presented of a patient with bony pains and abnormal radiological findings mistakenly diagnosed as multiple bone metastasis of unknown primary with extensive and expensive search for a primary tumor with no results. This case report provides an important lesson for the need to expand the differential diagnosis of abnormal bone radiological findings beyond the common metabolic and malignant diseases.

\section{Case Report}

Fifty six years old caucasian female presented to her primary care physician with the complaints of chronic lower back and neck pains. She has past medical history of bronchial asthma, microscopic hematuria, and osteoporosis. Her medications include calcium supplements, and alendronate. Her physical exam was normal including a normal neurological exam. Blood work including alkaline phosphatase were all within normal range. Lumbo-sacral $\mathrm{X}$-ray revealed suspicious osteoblastic lesions in the lumber vertebrae, right iliac crest and the left sacro-iliac joint, subsequently a computerized tomography scan of the pelvis showed multiple areas of increased bone density with surrounding cortical bone destruction in the left ischeal bone, right iliac crest and the left sacro-iliac joint suggestive of osteoblastic metastasis (Fig.-1).

Tc 99 whole body bone scan showed multiple bony lesions in the cervical, thoracic and lumber vertebrae, lower sternum, left ischial bone, right iliac crest, and the left posterior 6th rib, right femoral bone suggestive of multiple bone metastasis. (Fig.-2, 3)

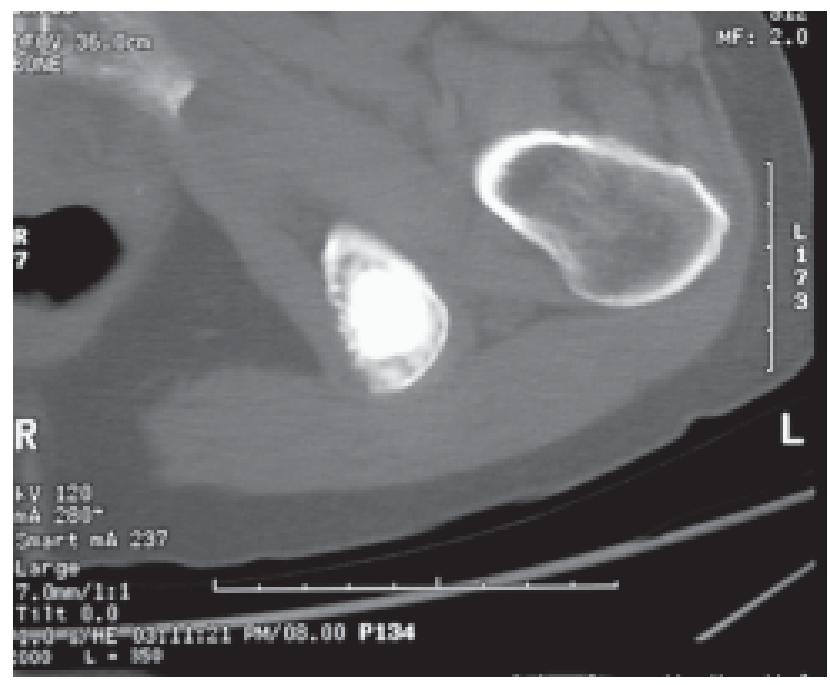

Fig.-1: Computerized tomography of the pelvis showing hyperdense lesion (Polka Dot) in the left ischial bone

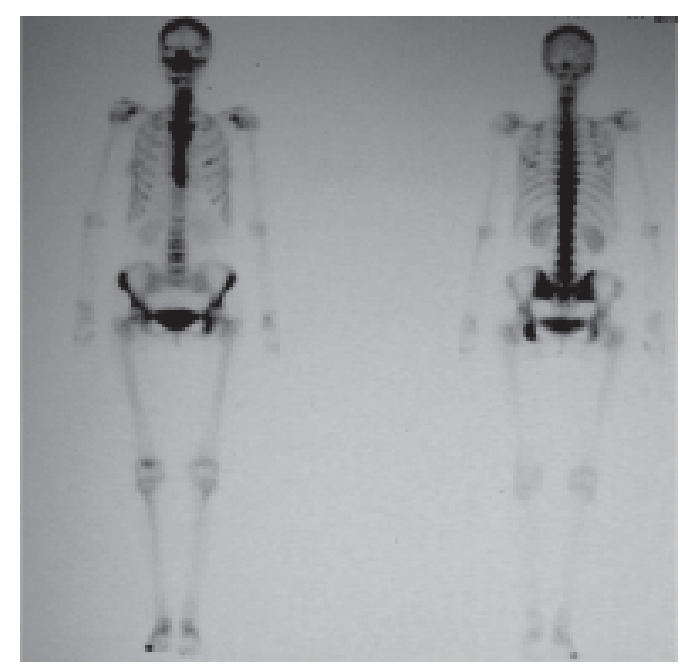

Fig.-2: Bone scan using Technetium 99 showing increased uptake in sternum, vertebral bodies (cervical, thoracic and lumbar), ribs, right femur and pelvic bones 


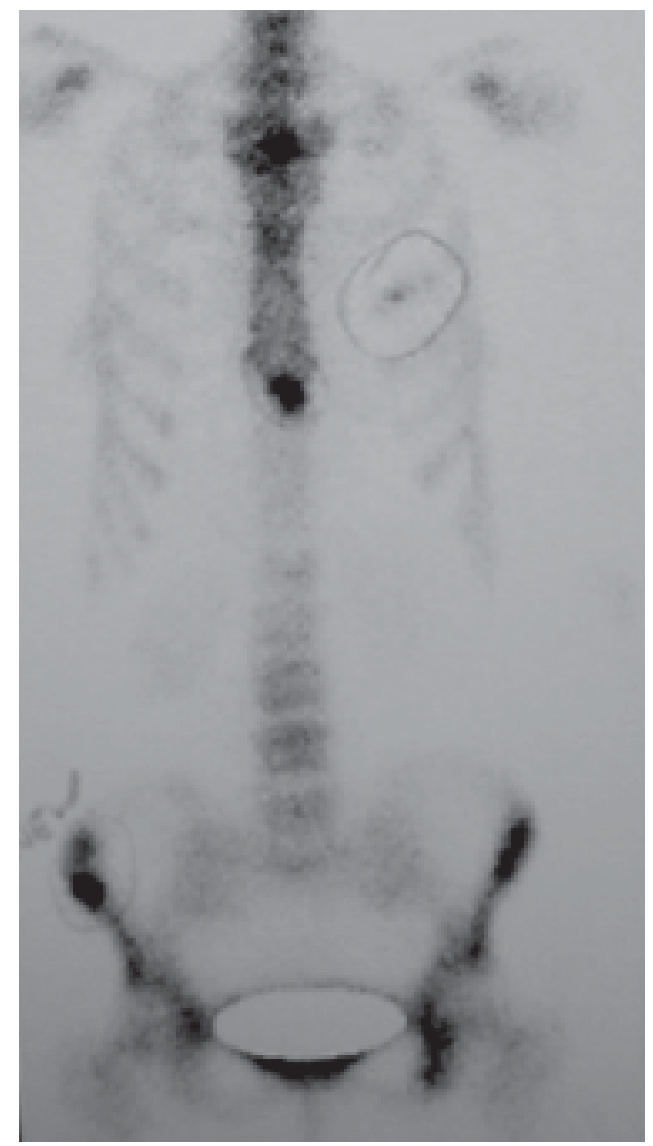

Fig.-3: Larger magnification of the bone scan again showing increased uptake in different sites.

Extensive workup to locate the primary tumor including chest $\mathrm{X}$-ray, computerized tomography scan of the chest, abdomen and pelvis, bilateral mammogram, pap smear, pelvic ultrasound, bone marrow aspiration biopsy, upper gastro intestinal series, and cystoscopy were all unrewarding. Finally the patient underwent a direct bone biopsy from the left pelvic area which was conclusive of sclerosing type of bone hemangioma of benign features. The patient was treated conservatively with analgesics.

In one year follow up, the patient was doing well and pain free, follow up radiological imaging studies showed the same findings with no new lesions and no change in the sizes of the lesions.

\section{Discussion}

Bone hemangiomas are rare benign tumors of the bones of vascular origin, first described by the German pathologist Virchow in $1867 .^{1,2}$ They count for $0.7 \%$ to $1 \%$ of all bone neoplasm's, however the identification of vertebral body hemangiomas in about $10 \%$ of autopsies indicate that they occur more often. ${ }^{3-6}$ Hemangiomas can be: a) solitary and localized in $66 \%$ of cases, b) multiple, occurring in non contiguous bones usually the vertebrae in $34 \%$ of cases or c) rarely are part of generalized type involving the liver, spleen, lung, skin, and bones called systemic angiomatosis. ${ }^{7,8}$ Most of bony hemagiomas are found in the vertebral bodies with predilection for the thoracic spines compared to the lumber, cervical or sacral spines, less commonly in the calvarium, and rarely in long bones, they are most often encountered in the fourth or fifth decade of life and have three to one female to male ratio. . $^{7,9,10,11}$

To our knowledge, very few cases had been reported about multiple bone hemangiomas involving both the vertebral column and the peripheral bones. ${ }^{12-15}$

Most of bone hemangiomas are asymptomatic and are discovered incidentally on routine $\mathrm{X}$-rays or they can cause symptoms of pain, visible or palpable deformity of the affected bones, or occasionally osteomalacia with pathologic fractures. ${ }^{16-18}$ Neurological complications and deficits secondary to spinal cord compression can occur depending on the level of vertebrae involved. ${ }^{14,19,20}$ Malignant transformation of primary bone hemangiomas are not known to occur. ${ }^{21}$

Grossly, hemangiomas are cystic, dark red cavitary masses. Histologically, they are usually classified into: a) capillary type, b) cavernous type, c) venous type and d) arteriovenous type. The capillary type is the most common and most often involves the vertebral bodies, while the cavernous type involves the calvarium more. Secondary changes or variants of bone hemangiomas were described: a) papillary, b) epithelioid, c) sclerosing. Those variants are frequently misdiagnosed as malignant vascular neoplasms.1,16,17,22,23

The thickened vertical trabeculae of hemangiomas cause parallel linear densities on plain x-ray films described as "Jail bar" or the classic: "corduroy", "honeycomb”, "sunburst", or "soap bubble" like appearance. ${ }^{11,23}$ Computerized tomography scan imaging mirrors the roentgen graphic appearance, demonstrating expanded lytic areas surrounded by coarse trabecular bone called the "polka dot" pattern. The calvarial lesions are usually lytic and resemble the 'radiating wheel spokes', the metaphyseal and epiphyseal lesions are also lytic and give a speculated pattern known as 'Irish lace'. ${ }^{23-25}$ Bone scintigraphy usually shows increase uptake in those lesions. ${ }^{11}$ Magnetic resonance imaging provides the clearest description of the extent of the hemangiomas, the lesions are low to intermediate signal intensity on the T1 weighted images, but markedly hyper intense on T2 weighted images. ${ }^{25,26}$

Diagnosis is often is based on radiological appearance but sometimes can be difficult and a direct bone biopsy may be 
needed to differentiate from other bone neoplasms, cysts, or metastasis. $^{22}$

The management of bone hemangiomas depends on the severity of symptoms and the location of the tumor. Conservative approach if symptoms are mild using analgesics been successful in many cases. Radiotherapy with total doses of 34 to $40 \mathrm{~Gy}$ has been used successfully especially in cases of vertebral hemangiomas causing spinal cord compression.27,28 Other treatment options include: transarterial embolization, ethanol sclerotherapy, vertebroplasty, and balloon kyphoplasty, all of which been proven effective in case reports. ${ }^{29-32}$ Patients with persistent pain or neurological symptoms despite the previous therapies might benefit from definitive surgical resection with or without radiotherapy. ${ }^{20,33}$

\section{Conflict of interest: None}

\section{References}

1. Murphy MD, Fairbairn KJ, Parman LM, et al. From the archives of the AFIP. Musculoskeletal angiomatous lesions: radiologic-pathologic correlation. Radiographics 1995; 15:893-917

2. Virchow R. Die krankhaften Geschwülste. Vol 1-3, Heft 1. A Hirschwald, Berlin, 1863-1867. [German]

3. Hook S, Font R, McCarty J, et al. Intraosseous capillary hemangioma of frontal bone. Am J Ophthalmol 1987; 103:824-7

4. Peterson DL, Murk SE, Story JL. Multifocal cavernous hemangioma of the skull: report of a case and review of the literature. Neurosurgery 1992; 30:778-81

5. Junghanns H. Über die Häufigkeit gutartiger Geschwülste inden Wirbelkörpern (Angiome, Lipome, Oste'ome). Arch F Klin Chirurgie 1932; 169:204-212 [German]

6. Hillman J, Bynke O. Solitary extradural cavernous hemangiomas in the spinal canal: report of five cases. Surg Neurol 1991; 36(1):19-24

7. Scott WA. Magnetic resonance imaging of the brain and spine. 3rd edn. Philladelphia: Lippincott Williams \& Wilkins; 2002;1720

8. Sainani NI, Pungavkar SA, Patkar DP, et al. Multiple hemangiomas involving the vertebral column. Acta Radiol 2005; 46:510-513

9. Greenspan A, Remagen W. Differential Diagnosis of Tumors and Tumor-like Lesions of Bones and Joints. Philadelphia: Lippincott-Raven, 1998:293

10. Devaney K, Vinh T, Sweet D. Skeletal-Exraskeletal angiomatosis. Am J Bone Joint Surg 1994;76:878-891
11 Rodallec MH, Feydey A, Larousserie F, et al. Diagnostic imaging of solitary spinal tumors of the spine: What to do and say. Radiographics 2008; 28:1019-41

12 Kulshrestha M, Byrne P. Multiple primary haemangiomas of bone mimicking vertebral metastases. J R Soc Med 1997; 90:632-634

13 Karlin CA, Brower AC. Multiple primary hemangiomas of bone. Am J Roentgenol 1977; 129:162-164

14 Wallis LA, Asch T, Maisel BW. Diffuse skeletal hemangiomatosis: report of two cases and review of literature. Am J Med 1964; 37:545-563

15 Zito G, Kadis GN. Multiple vertebral hemangiomas resembling metastases with spinal cord compression. Arch Neurol 1980; 37:247-8

16 Dahnert W. Haemangioma, bone. In: Radiology Review Manual. 4th ed. 1999:76-7

17 Resnik D, Kyriakos M, Greenway GD. Tumors and tumorlike lesions of bone. 4th ed. Diagnosis of Bone and Joint Disorders; 2002:3979-85.

18 McCarthy E, Frassica F. Tumor-Like Lesions. Pathology of bone and joint disorder with clinical and radiographic correlation. Philadelphia: Saunders; 1998:291

19 Aksu G, Fayda M, Saynak M, et al. Spinal cord compression due to vertebral hemangiomas. Orthopedics 2008; 31(2):169171

20 McAllister VL, Kendall BE, Bull JW. Symptomatic vertebral hemangiomas. Brain 1975; 98(1):71-80

21 Jaffe HL: Tumors and tumorous conditions of bones and joints. Philadelphia, PA, Lea \& Febiger, 1958

22 Huvos A. Bone Tumors. Diagnosis, Treatment and prognosis. $2^{\text {nd }}$ Ed, Philadelphia: WB Saunders CO, 1991

23 Osborn AG. Tumors, cysts and tumor like lesions of the spine and spinal cord. In: Diagnostic neuroradiology. St Louis: Mosby; 1994:876-918

24 Woertler K. Benign bone tumors and tumor like lesions: value of cross-sectional imaging. Eur Radiol 2003; 13:18201835

25 Cross JJ, Antoun NM, Laing RJC, et al. Imaging of compressive vertebral hemangiomas. Eur Radiol 2000; 10:997-1002

Ross JS, Masaryk TJ, Modic MT. Vertebral hemangiomas: MR imaging. Radiology 1987; 165:165-7

27 Heyd R, Seegenschmiedt MH, Rades D, et al. Radiotherapy for symptomatic vertebral hemangiomas: results of a multicenter study and literature review. Int J Radiat Oncol Biol Phys 2010; 77(1):217-225 
28 Bandiera S, Gasbarrini A, De lure F, et al. Symptomatic vertebral hemangiomas: the treatment of 23 cases and review of the literature. Chir Organi Mov 2002; 87(1):1-15

29 Acosta FL, Sanai N, Chi JH, et al. Comprehensive management of symptomatic and aggressive vertebral hemangiomas. Neurosurg Clin N Am 2008; 19:17-29

30 Crawford EA, Slotcavage RL, King JJ, et al. Ethanol sclerotherapy reduces pain in symptomatic musculoskeletal hemangiomas. Clin Orthop Relat Res 2009; 467:2955-2961
31 Peh WC, Gilula LA. Percutaneous vertebroplasty: indications, contraindications, and technique. Br J Radiol 20003; 76:69-75

32 Zapalowicz K, Skora P, Myslinski R, et al. Balloon kyphoplasty for painful C-7 vertebral hemangiomas. J Neurosurg Spine 2008; 9:458-461

33 Hsu W, Kosztowski TA, Zaidi HA, et al. Multidisciplinary management of primary tumors of the vertebral column. Curr Treat Options Oncol 2009; 10:107-125 